\section{INFLUENCE OF MAXIMAL ISOMETRIC STRENGTH ON 20-METER SPRINT TIME}

INFLUÊNCIA DA FORÇA ISOMÉTRICA MÁXIMA SOBRE OTEMPO EM SPRINTS DE ZOMETROS

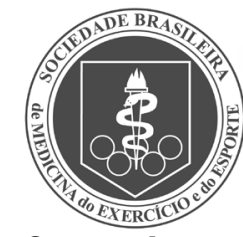

Original Article

Artigo Original Artículo Original

\author{
INFLUENCIA DE LA FUERZAUSOMÉTRICA MÁXIMA SOBRE EL TIEMPO EN SPRINTS DE 2OMETROS
}

Álvaro Huerta Ojeda' (DD (Physical Education Professional) Daniel Jerez-Mayorga² (ID (Physical Therapist)

Sergio Galdames Maliqueo 3 (D) (Physical Education Professional)

Darío Martínez García ${ }^{4}$ iD

(Physical Education and Sports Science)

Ángela Rodríguez-Perea ${ }^{4}$ (ID) (Physical Education and Sports Science Degree)

Leonidas Arias Poblete 2 (ID (Physical Therapist)

Ignacio Chirosa Ríos 4 (ID (Physical Education and Sports Science Degree)

Luis Javier Chirosa Ríos ${ }^{4}$ (ID (Physical Education and Sports Science Degree)

1. Universidad de Las Américas, Facultad de Educación, Grupo de Investigación en Salud, Actividad Física y Deporte (ISAFYD), Viña del Mar, Chile.

2. Universidad Andres Bello, Facultad de Ciencias de la Rehabilitación, Santiago, Chile. 3. Universidad de Playa Ancha, Facultad de la Actividad Física e del Deporte, Valparaíso, Chile.

4. Universidad de Granada, Facultad de Ciencias del Deporte, Department of Physical Education and Sports, Granada, Spain.

\section{Correspondence:}

Álvaro Huerta Ojeda. Avenida 7 Norte 1348, Viña del Mar, Chile. achuertao@yahoo.es

\begin{abstract}
Introduction: The squat is an exercise that is widely used for the development of strength in sports. However, considering that not all sports gestures are vertical, it is important to investigate the effectiveness of propulsive force stimuli applied in different planes. Objective: The main purpose of this study was to determine the influence of maximum isometric force (MIF) exerted on starting blocks over performance in 5, 10 and 20-meter sprints. Methods: Seven high-level male sprinters (mean age $\pm S D=28 \pm 5.77$ years) participated in this study. The variables were: a) MIF in squats and on starting blocks (measured using a functional electromechanical dynamometer [FEMD]), b) time in 5, 10 and 20-m sprints and c) jump height (measured by the squat jump test). For data analysis, a Pearson correlation was performed between the different variables. The criteria for interpreting the strength of the r coefficients were as follows: trivial $(<0.1)$, small $(0.1-0.3)$, moderate $(0.3-0.5)$, high $(0.5-0.7)$, very high $(0.7-0.9)$, or practically perfect $(>0.9)$. The level of significance was $p<0.05$. Results: There was very high correlation between MIF exerted on starting blocks and performance in the first meters of the sprint (5-m: $r=-0.84, p=0.01)$. However, there was small correlation between MIF in squats and performance in the first meters of the sprint $(5-\mathrm{m}: \mathrm{r}=-0.22, \mathrm{p}<0.62)$. Conclusion: The MIF applied on starting blocks correlates very high with time in the first meters of the sprint in high-level athletes. In addition, the use of the FEMD provides a wide range of possibilities for evaluation and development of strength with a controlled natural movement. Level of evidence IV; Prognostic Studies - Case series.
\end{abstract}

Keywords: Muscle strength; Isometric contraction; Athletes.

\section{RESUMO}

Introdução: O agachamento éum exercício amplamente utilizado para o desenvolvimento de força nos esportes. No entanto, considerando que nem todos os gestos esportivos são verticais, éimportante investigar a eficácia dos estímulos de força propulsiva em diferentes planos. Objetivo: O principal objetivo desteestudo foi determinar a influência da força isométrica máxima (FIM) exercida em os blocos delargada sobre o desempenho em sprints de 5, 10 e 20 metros. Métodos: Setevelocistas de alto nivel do sexo masculino (média $\pm D P=28,0 \pm 5,77$ anos) fizeram parte deste estudo. As variáveis foram: a) FIM no agachamento enos blocos de largada (avaliados com um dinamômetro eletromecânico funcional (DEF)), b) tempo de sprints de 5 , 10 e 20 metros ec) altura do salto (medida pelo teste de squatjump). Para análise dos dados, foi usada a correlação de Pearson entre as diferentes variáveis. Os critérios para interpretar o coeficiente rfoi: nulo $(<0,1)$, pequeno $(0,1$ a 0,3), moderado $(0,3$ a $0,5)$, alto $(0,5$ a 0,7), muito alto $(0,7$ a 0,9) ou praticamente perfeito $(>0,9)$. O nivel de significância foip $<0,05$. Resultados: Houve correlação muito alta entre a FIM exercida nos blocos de largadae o desempenho nos primeiros metros do sprint (5-m: $r=-0,84$, $p=0,01$ ). No entanto, a correlação entre o agachamento da FIM e os primeiros metros de sprint foi pequena (5-m: $r=-0,22, p<0,62$ ). Conclusão: A FIM aplicada aos blocos de largada teve uma correlação muito alto com o tempo nos primeiros metros de sprint em atletas de alto nível. Além disso, o uso de um DEF oferece uma ampla gama de possibilidades para avaliar e desenvolver força com um movimento natural controlado. Nível de evidência IV; Estudos Prognósticos - Série de casos.

Descritores: Força muscular; Contração isométrica; Atletas.

\section{RESUMEN}

Introducción: La sentadilla es un ejercicio ampliamente usado para el desarrollo de fuerza en los deportes. Sin embargo, considerando que no todos los gestos deportivos son verticales, es importante investigar la eficacia de los estímulos de fuerza propulsiva en diferentes planos. Objetivo: El principal objetivo de este estudio fue determinar la influencia de la fuerza isométrica máxima (FIM) ejercida en los bloques de salida sobre el rendimiento en sprints de 5, 10y 20 metros. Métodos: Siete velocistas de alto nivel del sexo masculino (promedio $\pm S D=28,0 \pm 5,7$ años) formaron parte de este estudio. Las variables fueron: a) FIM en la sentadilla y en los bloques de salida (evaluados con un dinamómetro electromecánico funcional [DEF]) b) tiempo de sprints de 5, 10 y 20-metros y c) altura del salto (medida a través del test de squat jump). Para el análisis de los datos se usó la correlación de Pearson entre las diferentes variables. Los criterios para interpretar el coeficiente rfueron: nulo $(<0,1)$, pequeño $(0,1 \mathrm{a} 0,3)$, moderado $(0,3 \mathrm{a} 0,5)$, alto $(0,5$ a 0,7$)$, muy alto $(0,7$ a 0,9) o prácticamente perfecto $(>0,9)$. El nivel de significancia fue $p<0,05$. Resultados: Hubo correlación muy alta entre 
la FIM ejercida en los bloques de salida y el rendimiento en los primeros metros del sprint ( $5-m$ : $r=-0,84, p=0,01)$. Sin embargo, la correlación entre la FIM en sentadilla y los primeros metros de sprint fue pequeña $(5-m: r=-0,22, p<0,62)$. Conclusión: La FIM aplicada a los bloques de salida tuvo una correlación muy alta con el tiempo en los primeros metros de sprint en atletas de alto nivel. Además, el uso de un DEF ofrece una amplia gama de posibilidades para evaluary desarrollar fuerza con un movimiento natural controlado. Nivel de evidencia IV; Estudios pronósticos: Serie de casos.

Descriptores: Fuerza muscular; Contracción Isométrica; Atletas.

\section{INTRODUCTION}

Back squat is a widely used exercise for the development of strength in sports ${ }^{1,2}$ which increases force levels in the lower extremities., ${ }^{2,3}$ However, some studies emphasize that not all sports gestures are vertical ${ }^{1,2}$ these studies evidence that some trainings are more effective than squats for strength development in the lower-body, concluding that the effectiveness of the stimulus may be conditioned to the vector planes of the propulsive force. ${ }^{4}$

In relation to the increase in performance in velocity athletic tests, different training methodologies have been used. ${ }^{2,5}$ However, and under the vector parameters of force application, most of these investigations have applied nonspecific exercises when compared to real sports movements. ${ }^{6}$ While there is a transference from the vertical forces developed through squats towards horizontal forces (sprint performance), ${ }^{2,3}$ it is also important to analyze studies that have reported a decrease in the magnitude of correlations between vertical and horizontal forces in high-level athletes.

Currently, there are several tools for evaluating strength and speed.8 However, the assessment and training of strength in sprinters should be similar to the gestures developed in competitions. ${ }^{7}$ For example, sprinters should consider force assessments on starting blocks.

According to the characteristics of the sprinters and the specificity of the start from starting blocks, it seems that a quick start off is a key factor for the performance in the first 20 meters (20-m) of sprint. ${ }^{10}$ However, the maximal isometric force (MIF) on starting blocks and its relation to performance in the first few meters of the sprint has not been evaluated. ${ }^{10}$ To help with these relation, there are functional electromechanical dynamometers (FEMDs) that allow to execute evaluation in similar conditions from competition, specifically in vector planes and muscular contractions. ${ }^{11}$

Considering that the isometric force is present during the "set" position on starting blocks and that, nowadays, there are devices that allow quantifying the strength exerted in different vector planes, the primary aim of this study was to determine the influence of MIF on starting blocks over time performance in 5, 10 and 20-m sprints. The secondary objectives were to relate the MIF exerted on starting blocks to the height of jump. In addition, the hypothesis of this study was that there is a high relation between the MIF exerted on starting blocks and time performance in 20-m sprints.

\section{METHODS}

\section{Experimental approach to the problem}

This was a quantitative research with a pre-experimental design. The inclusion criterion was previous performance in 100-m sprint tests (during the 2019 season, athletes had to reach a run time of less than 10.95 seconds [s] in the 100-m sprint). Exclusion criteria were: the prevalence of musculoskeletal injuries, the inability to perform maximum isometric tests, the inability to perform start from starting blocks or the inability to perform SJ tests.

\section{Participants}

Seven high-level male sprinters volunteered to participate in this study. (Table 1) All participating athletes and coaches were informed of the objectives of the study and the possible risks of the experiment. In addition, they signed an informed consent prior to the application of the protocol. Both, the study protocol and the informed consent were approved by the Human Research Ethics Committee of the University of Granada, Spain (registry 493/CEIH/2019) and conformed to the standards of the latest revision of the Declaration of Helsinki.

\section{Testing protocol}

Evaluation day 1: after the warm-up, the subjects performed four exercise modalities with maximal isometric contractions of the lower-body: I) isometric squat with knee flexion at $90^{\circ}$. In this execution, the lateral separation of the feet was the projection of the width of the shoulders towards the floor (both soles were supported, the back was straight and the hands were laying on the hips). (Figure 1A) II) Isometric squat with dominant knee forward and flexed at $90^{\circ}$. In this test, the anteroposterior separation of the feet was $1 \mathrm{~cm}$ between the heel of the forefoot and the tip of the delayed foot. The measurement of the angle of $90^{\circ}$ was executed in the knee of the forefoot, while the lateral

Table 1. Characteristics of the sample (mean \pm SD).

\begin{tabular}{|c|c|c|c|c|c|c|c|c|c|}
\hline Participants & Age (years) & Dominant foot & $\begin{array}{l}\text { Best record in } \\
100-\mathrm{m}(\mathrm{s})\end{array}$ & Experience (years) & Weight (Kg) & Body Mass (m) & $\begin{array}{c}\text { BMI } \\
\left(\mathrm{kg} / \mathrm{m}^{2}\right)\end{array}$ & Body fat (\%) & MIFS/BM \\
\hline a & 25 & Left & 10.94 & 16 & 76.4 & 1.88 & 21.6 & 6.1 & 0.73 \\
\hline b & 24 & Left & 10.94 & 10 & 74.6 & 1.78 & 23.5 & 11.1 & 1.54 \\
\hline c & 26 & Right & 10.49 & 5 & 88.4 & 1.90 & 24.5 & 8.5 & 0.95 \\
\hline$d$ & 24 & Right & 10.31 & 9 & 71.5 & 1.80 & 22.1 & 6.9 & 1.00 \\
\hline $\mathrm{e}$ & 39 & Left & 10.92 & 25 & 71.4 & 1.74 & 23.7 & 10.4 & 0.98 \\
\hline$f$ & 33 & Right & 10.62 & 20 & 74.3 & 1.81 & 22.7 & 7.5 & 1.52 \\
\hline g & 25 & Right & 10.90 & 10 & 79.8 & 1.71 & 27.3 & 12.5 & 1.18 \\
\hline mean & 28.0 & ----- & 10.73 & 13.6 & 76.6 & 1.80 & 23.6 & 9.0 & 1.13 \\
\hline SD & 5.77 & ------ & 0.26 & 7.04 & 5.94 & 0.07 & 1.89 & 2.38 & 0.30 \\
\hline
\end{tabular}

Seconds (s), kilograms (Kg), meters (m): body mass index (BMI), maximal isometric force in squat (MIFS), body mass (BM), standard deviation (SD). 


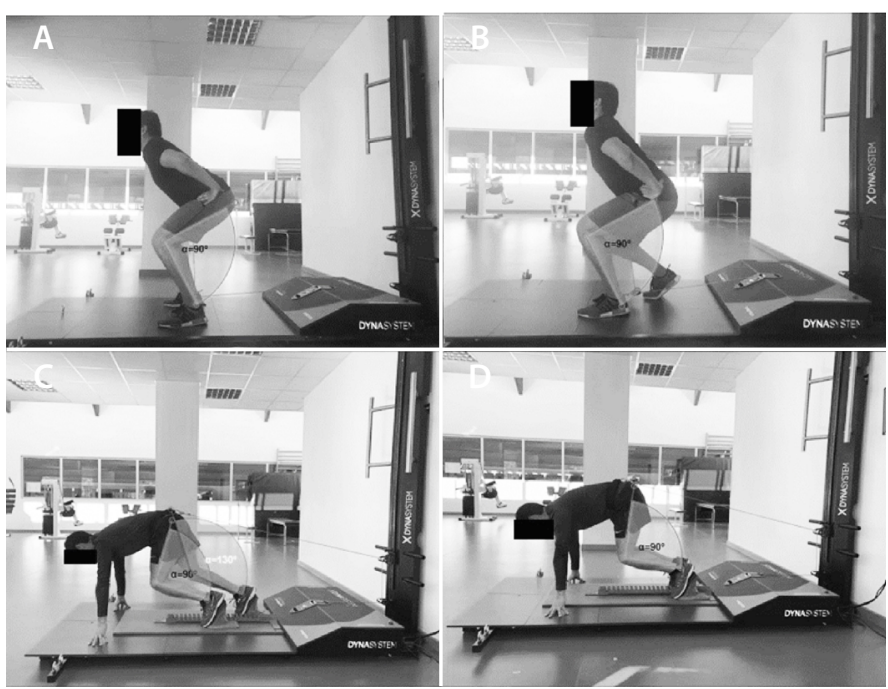

Figure 1. Evaluation of maximal isometric forces. Isometric squat with knee flexion at $90^{\circ}(\mathrm{A})$, isometric squat with dominant knee forward and flexed at $90^{\circ}(\mathrm{B})$, maximal isometric force of the lower-body exerted on starting blocks with dominant knee forward and flexed at $90^{\circ}(\mathrm{C})$, maximal isometric force of the lower-body exerted on starting blocks with both knees at $90^{\circ}(\mathrm{D})$.

separation of the feet was the projection of the width of shoulders towards the floor. In this execution, the forefoot supported the whole sole while the delayed foot only supported the metatarsal (straight back and hands laying on hips). (Figure 1B) III) MIF of the lower-body exerted on starting blocks with dominant knee forward and flexed at $90^{\circ}$, delayed knee flexed at $130^{\circ}$. In this test, the lateral separation of the feet was given by the structure of the starting blocks. In this execution both soles rested on the entire surface of the starting blocks, the back was straight and hands never lost contact with the floor ("set" position). (Figure 1C) IV) MIF of the lower-body exerted on starting blocks with both knees at $90^{\circ}$, the lateral separation of the feet was given by the structure of the starting blocks. In this test, both soles were supported on the entire surface of the starting blocks, the back was straight and the hands never lost contact with the floor ("set" position). (Figure 1D)

The MIF for the four modalities was evaluated for $5 s^{12}$ with a FEMD (Dynasystem ${ }^{\circledR}$, Symotech, Granada, Spain). The FEMD allows kinetic-tonic control of the movement $\left(0.10-1.5 \mathrm{~m} \cdot \mathrm{s}^{-1}\right)$ and isometric assessment of muscle strength $(5-3000 \mathrm{~N})$ with a sampling frequency of $1.000 \mathrm{~Hz}$ (Dynasystem, Model Research, Granada, Spain). ${ }^{11}$ The MIF, expressed in newtons, was recorded and used in the subsequent statistical analysis. The order of the exercises was cross-referenced for the entire sample.

Evaluation day 2: after the warm-up, in the 20-m sprint, the time was measured in milliseconds (ms) from the starting on starting blocks; for the statistical analysis, it was considered the time performance (ms) from the starting block until 5, 10 and $20 \mathrm{~m}$ of the sprint. The evaluation was performed using a photoelectric cell (Microgate ${ }^{\circledR}$ model Polifemo SF Radio, Bolzano, Italy) with a radius transmission range of approximately $2 \mathrm{~km}$ and a reflective operation with a range of more than $35 \mathrm{~m}$ in an athletics track. For the starts from the starting blocks, there were used audible athletic competition signals:"on your marks","set" and the sound of a starting gunfire. Starting blocks were Polanik ${ }^{\circledR}$ (Piotrków Trybunalski, Poland).

Squat Jumps were measured in $\mathrm{cm}$ from a bipodal position, with knees angled at $90^{\circ}$, hands on hips and no countermovement. ${ }^{13}$ The evaluation was carried out using a jumping mat (Optojump ${ }^{\circledR}$, Bolzano, Italy). The carpet contains 96 infrared LEDs $(1.0416 \mathrm{~cm}$ resolution). These LEDs are located on the transmitting bar and communicate continuously with the LEDs located on the receiving bar. The system detects interruptions and their duration. The order of the exercises was cross-referenced for the entire sample.

\section{Statistical analysis}

The variables were analyzed in the Shapiro-Wilk normality test. Then, a Pearson correlation analysis was performed between the different maximal isometric exercises and time performance in 5, 10 and 20-m sprints. The level of significance for all statistical analyses was $p<0.05$.

\section{RESULTS}

The descriptive characteristics of jumping heights in $\mathrm{SJ}$ tests and time performance in 5, 10 and 20-m sprints are presented in Table 2. In addition, the absolute and relative values (peak and mean) for the four modalities of MIF ( 2 in squat and 2 on starting blocks) are shown in Table 3.

The Pearson's test showed a very high correlation between $\mathrm{SJ}$ tests and the 100-m personal best mark reported by sprinters $(r=-0.88$, $p=0.007$ ). (Table 4) On the other hand, low correlations were obtained in the absolute maximal isometric squat and the first meters of sprint (absolute peak values and 5-m sprint: $r=-0.22, p=0.62$; absolute mean values and 5-m sprint: $r=-0.33, p=0.45$ ). (Table 4 and Figure 2A) Likewise, very low correlation were obtained between the relative maximal isometric squat and the first meters of sprint (relative peak values and 5-m sprint: $r=-0.08, p=0.85$; relative mean values and 5-m sprint: $r=-0.21, p=0.64$ ). (Table 4 and Figure $2 B$ )

The Pearson's test showed a moderate correlation between absolute isometric squat, with dominant knee forward and flexed at $90^{\circ}$, and the first meters of sprint (absolute peak values and 5-m sprint: $r=-0.65, p=$ 0.11; absolute mean values and $5-m$ sprint: $r=-0.65, p=0.25$ ). (Table 4 and Figure 2C) Likewise, high correlation were obtained in the relative isometric squat, with dominant knee forward and flexed at $90^{\circ}$, and the first meters of sprint (relative peak values and $5-m$ sprint: $r=-0.49, p=$ 0.25 ; relative mean values and $5-m$ sprint: $r=-0.53, p=0.21$ ). (Table 4 and Figure 2D)

On the other hand, the Pearson's test showed a moderate correlation between the absolute MIF of the lower-body exerted on starting blocks, with dominant knee forward and flexed at $90^{\circ}$, and the first 5-m sprint ( $r=-0.70, p=0.07$ ). (Table 4 and Figure $2 E-F$ ) In addition, there was a moderate correlation between the absolute MIF of the lower-body exerted on starting blocks, with dominant knee forward and flexed at $90^{\circ}$, and the first 10 and $20-\mathrm{m}$ sprint (10 m: $r=-0.48, p=0.27 ; 20 \mathrm{~m}$ : $r=-0.46, p=0.29$ ). (Table 4)

The Pearson's test showed a high correlation between absolute MIF of the lower-body exerted on starting blocks, with both knees at $90^{\circ}$, and the first 5-m sprint (absolute peak values and 5-m sprint: $r=-0.84$, $p=0.01$; absolute mean values and 5-m sprint: $r=-0.82, p=0.02$ ). (Table 4 and Figure $2 \mathrm{G}$ ) In addition, there was a very high correlation between the relative MIF of the lower-body exerted on starting blocks, with both knees at $90^{\circ}$, and the first 5-m sprint (relative peak values and 5-m sprint: $r=-0.76, p=0.04$; relative mean values and 5-m sprint: $r=-0.74$, $\mathrm{p}=0.05)$. (Table 4 and Figure $2 \mathrm{H}$ )

Table 2. Squat jump and run values in 5, 10 and 20-m sprints.

\begin{tabular}{c|c|c|c|c}
\hline Participants & $\begin{array}{c}\text { SJ } \\
(\mathbf{c m})\end{array}$ & 5-m sprint (ms) & 10-m sprint (ms) & 20-m sprint (ms) \\
\hline $\mathrm{a}$ & 42.8 & 1070 & 1755 & 2905 \\
\hline $\mathrm{b}$ & 46.6 & 1085 & 1775 & 2965 \\
\hline $\mathrm{c}$ & 53.5 & 995 & 1650 & 2785 \\
\hline $\mathrm{d}$ & 56.5 & 1025 & 1715 & 2875 \\
\hline $\mathrm{e}$ & 46.7 & 1070 & 1735 & 2960 \\
\hline $\mathrm{f}$ & 46.3 & 971 & 1624 & 2755 \\
\hline $\mathrm{g}$ & 41.8 & 985 & 1763 & 3038 \\
\hline mean & 47.7 & 1028 & 1716 & 2897 \\
\hline SD & 5.38 & 46 & 58 & 101 \\
\hline SJ (Squat Jump) centimeters (cm) milliseconds (ms), standard deviation (SD).
\end{tabular}


Table 3. Maximal isometric force values in squat and starting blocks (absolute and relative).

\begin{tabular}{|c|c|c|c|c|c|c|c|c|c|c|c|c|c|c|c|c|}
\hline \multirow{3}{*}{ Participants } & \multicolumn{4}{|c|}{$\begin{array}{c}\text { Isometric squat } \\
\left.\text { (both knees flexed at } 90^{\circ}\right)\end{array}$} & \multicolumn{4}{|c|}{$\begin{array}{l}\text { Isometric squat (dominant knee } \\
\text { forward and flexed at } 90^{\circ} \text { ) }\end{array}$} & \multicolumn{4}{|c|}{$\begin{array}{l}\text { Starting blocks (dominant knee } \\
\text { forward and flexed at } 90^{\circ} \text { ) }\end{array}$} & \multicolumn{4}{|c|}{$\begin{array}{c}\text { Starting blocks } \\
\text { (both knees flexed at } 90^{\circ} \text { ) }\end{array}$} \\
\hline & \multicolumn{2}{|c|}{ absolute (N) } & \multicolumn{2}{|c|}{ relative $(\mathrm{N})$} & \multicolumn{2}{|c|}{ absolute (N) } & \multicolumn{2}{|c|}{ relative $(\mathrm{N})$} & \multicolumn{2}{|c|}{ absolute (N) } & \multicolumn{2}{|c|}{ relative $(\mathrm{N})$} & \multicolumn{2}{|c|}{ absolute (N) } & \multicolumn{2}{|c|}{ relative (N) } \\
\hline & $\begin{array}{l}\text { peak } \\
\text { force }\end{array}$ & $\begin{array}{l}\text { mean } \\
\text { force }\end{array}$ & $\begin{array}{l}\text { peak } \\
\text { force }\end{array}$ & $\begin{array}{l}\text { mean } \\
\text { force }\end{array}$ & $\begin{array}{l}\text { peak } \\
\text { force }\end{array}$ & $\begin{array}{l}\text { mean } \\
\text { force }\end{array}$ & $\begin{array}{l}\text { peak } \\
\text { force }\end{array}$ & $\begin{array}{l}\text { mean } \\
\text { force }\end{array}$ & $\begin{array}{l}\text { peak } \\
\text { force }\end{array}$ & $\begin{array}{l}\text { mean } \\
\text { force }\end{array}$ & $\begin{array}{l}\text { peak } \\
\text { force }\end{array}$ & $\begin{array}{l}\text { mean } \\
\text { force }\end{array}$ & $\begin{array}{l}\text { peak } \\
\text { force }\end{array}$ & $\begin{array}{l}\text { mean } \\
\text { force }\end{array}$ & $\begin{array}{l}\text { peak } \\
\text { force }\end{array}$ & $\begin{array}{l}\text { mean } \\
\text { force }\end{array}$ \\
\hline$a$ & 734.0 & 547.5 & 9.607 & 7.166 & 566.0 & 482.9 & 7.408 & 6.320 & 763,5 & 675.4 & 9.993 & 8.831 & 483.0 & 450.8 & 6.321 & 5.898 \\
\hline$b$ & 1256.0 & 1122.8 & 16.836 & 15.052 & 868.0 & 770.5 & 11.635 & 10.329 & 712,0 & 622.1 & 9.537 & 8.33 & 520.0 & 470.5 & 6.970 & 6.306 \\
\hline c & 933.0 & 826.9 & 10.554 & 9.354 & 841.0 & 712.4 & 9.513 & 8.059 & 789,0 & 706.7 & 9.375 & 7.994 & 612.0 & 549.2 & 6.923 & 6.208 \\
\hline$d$ & 789.0 & 699.9 & 11.034 & 9.788 & 699.0 & 605.8 & 9.776 & 8.472 & 741,0 & 615.9 & 10.363 & 8.614 & 469.5 & 435.7 & 6.566 & 6.093 \\
\hline $\mathrm{e}$ & 744.0 & 685.3 & 10.42 & 9.598 & 808.0 & 706.2 & 11.316 & 9.891 & 615,5 & 550.6 & 8.620 & 7.710 & 461.0 & 443.1 & 6.456 & 6.185 \\
\hline$f$ & 1142.0 & 1105.5 & 15.37 & 14.879 & 1142.0 & 1083.6 & 15.37 & 14.584 & 803,0 & 708.7 & 10.498 & 9.526 & 784.0 & 719.1 & 10.552 & 9.687 \\
\hline $\mathrm{g}$ & 1016.0 & 924.1 & 12.732 & 11.580 & 968.0 & 916.3 & 12.13 & 11.482 & 724,0 & 688.6 & 9.073 & 8.629 & 783.0 & 747.5 & 9.812 & 9.367 \\
\hline mean & 944.8 & 844.6 & 12.365 & 11.059 & 841.7 & 753.9 & 11.021 & 9.877 & 735,4 & 652.6 & 9.637 & 8.519 & 587.5 & 545.1 & 7.657 & 7.106 \\
\hline SD & 204.1 & 218.5 & 2.756 & 2.961 & 184.5 & 197.7 & 2.499 & 2.672 & 62,3 & 58.5 & 0.686 & 0.591 & 143 & 134.2 & 1.753 & 1.66 \\
\hline
\end{tabular}

Newton (N).

Table 4. Correlations between maximal isometric force variables and first meters of sprint $(n=7)$.

\begin{tabular}{|c|c|c|c|c|c|}
\hline \multicolumn{2}{|l|}{ Pearson Correlation } & $\begin{array}{c}5-m \\
\text { sprint }\end{array}$ & $\begin{array}{c}10-m \\
\text { sprint }\end{array}$ & $\begin{array}{c}20-m \\
\text { sprint }\end{array}$ & $\begin{array}{l}100-\mathrm{m} \\
\text { sprint }\end{array}$ \\
\hline SJ & $r$ & -0.129 & -0.432 & -0.504 & $-0.886^{* *}$ \\
\hline $\begin{array}{l}\text { Isometric squat (both knees flexed at } 90^{\circ} \text { ) } \\
\text { Absolute peak values }\end{array}$ & r & -0.228 & -0.105 & -0.051 & 0.131 \\
\hline $\begin{array}{l}\text { Isometric squat (both knees flexed at } 90^{\circ} \text { ) } \\
\text { Absolute mean values }\end{array}$ & r & -0.337 & -0.224 & -0.106 & 0.046 \\
\hline $\begin{array}{l}\text { Isometric squat (both knees flexed at } 90^{\circ} \text { ) } \\
\text { Relative peak values }\end{array}$ & r & -0.085 & -0.019 & 0.009 & 0.167 \\
\hline $\begin{array}{l}\text { Isometric squat (both knees flexed at } 90^{\circ} \text { ) } \\
\text { Relative mean values }\end{array}$ & r & -0.214 & -0.151 & -0.056 & 0.077 \\
\hline $\begin{array}{l}\text { Isometric squat (dominant knee } \\
\text { forward and flexed at } 90^{\circ} \text { ) } \\
\text { Absolute peak values }\end{array}$ & r & -0.653 & -0.486 & -0.215 & -0.036 \\
\hline $\begin{array}{l}\text { Isometric squat (dominant knee } \\
\text { forward and flexed at } 90^{\circ} \text { ) } \\
\text { Absolute mean values }\end{array}$ & r & -0.659 & -0.438 & -0.166 & 0.003 \\
\hline $\begin{array}{c}\text { Isometric squat (dominant knee } \\
\text { forward and flexed at } 90^{\circ} \text { ) } \\
\text { Relative peak values }\end{array}$ & r & -0.496 & -0.396 & -0.153 & 0.005 \\
\hline $\begin{array}{l}\text { Isometric squat (dominant knee } \\
\text { forward and flexed at } 90^{\circ} \text { ) } \\
\text { Relative mean values }\end{array}$ & r & -0.531 & -0.372 & -0.125 & 0.031 \\
\hline $\begin{array}{l}\text { Starting blocks (dominant knee } \\
\text { forward and flexed at } 90^{\circ} \text { ) } \\
\text { Absolute peak values }\end{array}$ & r & -0.228 & -0.105 & -0.051 & 0.131 \\
\hline $\begin{array}{l}\text { Starting blocks (dominant knee } \\
\text { forward and flexed at } 90^{\circ} \text { ) } \\
\text { Absolute mean values }\end{array}$ & r & -0.703 & -0.481 & -0.461 & -0.205 \\
\hline $\begin{array}{l}\text { Starting blocks (dominant knee } \\
\text { forward and flexed at } 90^{\circ} \text { ) } \\
\text { Relative peak values }\end{array}$ & r & -0.270 & -0.418 & -0.613 & -0.538 \\
\hline $\begin{array}{l}\text { Starting blocks (dominant knee } \\
\text { forward and flexed at } 90^{\circ} \text { ) } \\
\text { Relative mean values }\end{array}$ & r & -0.465 & -0.325 & -0.367 & -0.146 \\
\hline $\begin{array}{c}\text { Starting blocks (both knees flexed at } 90^{\circ} \text { ) } \\
\text { Absolute peak values }\end{array}$ & r & $-0.842^{*}$ & -0.416 & -0.159 & -0.021 \\
\hline $\begin{array}{l}\text { Starting blocks both knees flexed at } 90^{\circ} \text { ) } \\
\text { Absolute mean values }\end{array}$ & r & $-0.826^{*}$ & -0.355 & -0.079 & 0.025 \\
\hline $\begin{array}{c}\text { Starting blocks (both knees flexed at } 90^{\circ} \text { ) } \\
\text { Relative peak values }\end{array}$ & r & $-0.768^{*}$ & -0.376 & -0.125 & 0.01 \\
\hline $\begin{array}{l}\text { Starting blocks (both knees flexed at } 90^{\circ} \text { ) } \\
\text { Relative mean values }\end{array}$ & r & -0.748 & -0.314 & -0.046 & 0.056 \\
\hline
\end{tabular}

\section{DISCUSSION}

The main results of this study indicate that there is a high correlation between the MIF exerted on starting blocks and time in a 5 -m sprint in highlevel male sprinters $(r=-0.70, p=0.07)$. In recent studies similar correlation have been obtained between lower-body strength and sprinting time performances..$^{14,15}$ For example, the study of Andersen et al. ${ }^{14}$ showed a high correlation between relative lower-body strength and 10-m and 30-m sprints in collegiate women soccer players $(r=-0.59, p<0.05$ and $r=-0.67, p<0.01$, respectively); these authors concluded that relative lower-body strength is important since it improves power, agility, and speed performance. Likewise, the study of McBride et al. ${ }^{15}$ showed a moderate correlation between relative maximal squat strength (1RM/body mass) and performance in 5 and 10 yards $(r=-0.45, p=0.06$ and $r=-0.54, p=0.02$, respectively). They concluded that the level of strength of the lower-body musculature, in male football athletes, is an obvious site of interest for maximizing sprinting ability.

In a study of Janowski et al. ${ }^{10}$ it was aimed to evaluate individual kinematic characteristics in highly trained sprinters during the "set" position, block clearance and a 20-m acceleration phase; it was concluded that fast block clearance and stride symmetry are key factors affecting sprint performance during the 20-m acceleration phase. Despite these results, it is important to mention that rapid clearance not always mean that high levels of force or power are being exerted on starting blocks. In this sense, as previous researches on controlled natural movements, ${ }^{16}$ the use of the FEMDs made possible to cover non explored areas and generate knowledge applicable to sprinters, based on its isometric mode.

A relevant piece of information resulting from this research was the low correlation between the MIF in squat and the first meters of a sprint (5-m: $r=$ $-0.22, p=0.64 ; 10-m: r=-0.15, p<0.74 ; 20-m: r=-0.05, p=0.86)$. Possibly, the low correlations observed between squats and sprints are due to horizontal plans and vertical plans in the application of force, respectively; this suggests that the two tasks provide distinctive information regarding the force-velocity-power profile of lower-body muscles, especially in high-level sprinters and high-level athletes. ${ }^{7}$ Therefore, a key element to increase sport performance is determining the specific vector parameters for each sport reality. ${ }^{4,6}$

There are studies that have connected a higher jumping height with the force levels of the lower extremities. ${ }^{3}$ For example, Andersen et al. ${ }^{14}$ reported a high correlation between the relative lower-body strength and the vertical jump in collegiate women soccer players $(r=0.54, p<0.05)$; this authors concluded that the development of absolute and relative lower-body strength should be emphasized to increase speed performance. An important investigation for the comparison of results, due to the similarities to our study, is Carmona et al..$^{17}$ these researchers calculated a correlation of $-0.925(p>0.05)$ for the $S$ J and the 30-m sprint in female sprinters, concluding that the maximum speed is the main parameter 


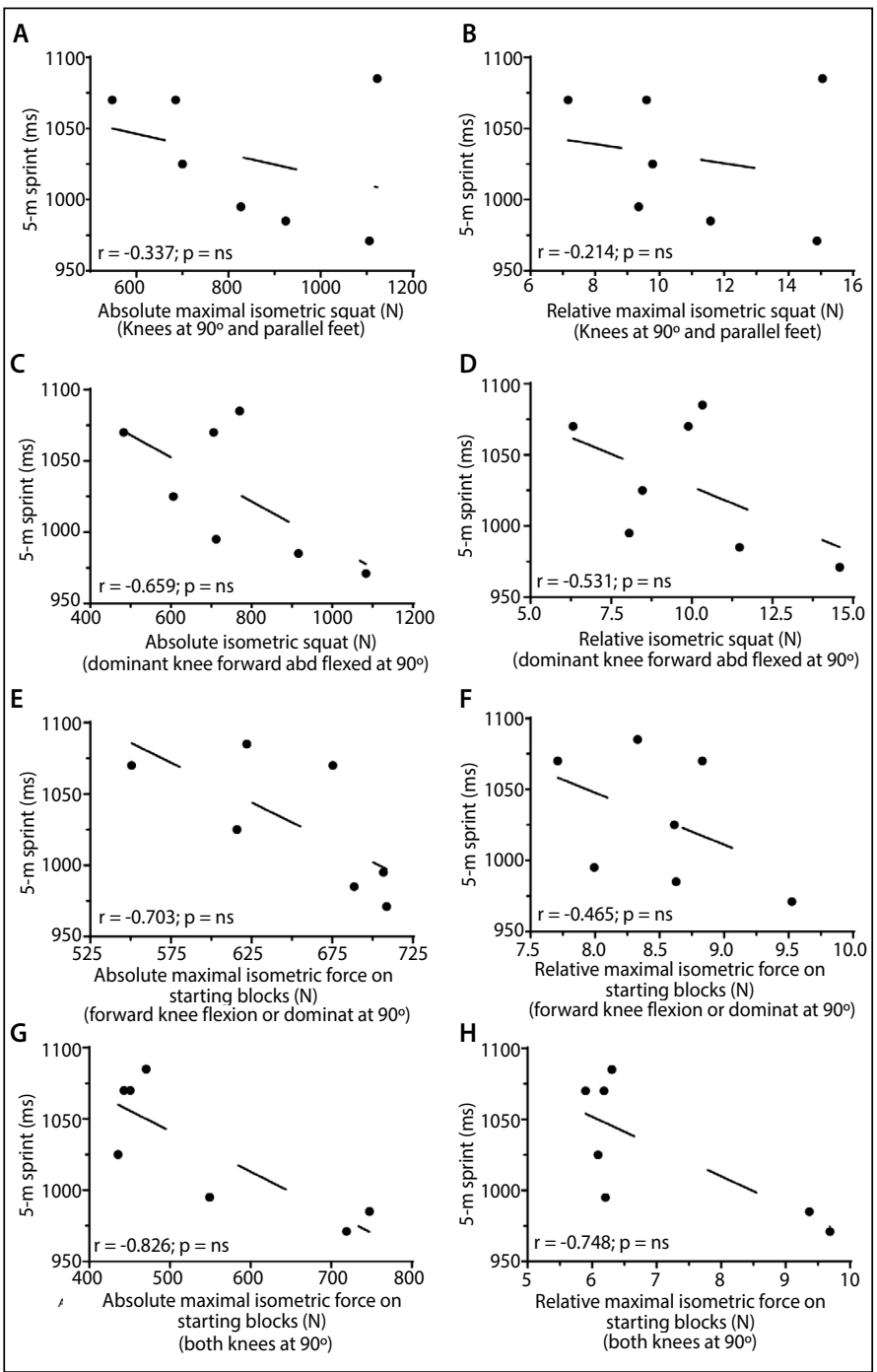

Figure 2. Relation between the maximal isometric forces and performance in 5-meter sprints. Newton (N), milliseconds (ms), ns (not significant). of performance in this population. However, in the present study, one of the analyses correlated were SJ and MIF exerted on starting blocks (dominant knee forward and flexed at $90^{\circ}$ ); at the end of the analysis, a very low correlation between both variables were evidenced $(r=-0.14 ; p$ $=0.75$ ). This result was similar to the one performed between the MIF in squat and time in the first meters of sprint ( $5-m: r=-0.22, p=0.64 ; 10-m: r$ $=-0.15, p<0.74 ; 20-m: r=-0.05, p=0.90)$. With the information described above it can be concluded that the jump and sprint tests have different values (horizontal vector and vertical vector); however, they complement each other to establish the force-velocity-power profile for each athlete. ${ }^{7}$

Both, the type of muscular contraction (MIF) and the sport-specific vector planes (starting blocks in sprinters) could be evaluated using DEMFs. These devices allowed the evaluation of force in similar conditions to competition, specifically in vector planes and muscular contractions. ${ }^{11}$ Therefore, the use of DEMFs is suggested, not only in rehabilitation, 11,18 but in all the realities of controlled natural motion.

\section{CONCLUSION}

In conclusion, at the end of the study it was possible to determine that the MIF on starting blocks has a high correlation over time performance in 5-m sprints. For this reason, it is concluded that high-levels of MIF have a positive influence on performance in the first meters of a sprint in high-level athletes, starting from the starting blocks.

Even though there are small correlations between the squat and the first meters of the sprint and between $\mathrm{SJ}$ and the first meters of the sprint, these values are relevant since they complement each other to establish the force-velocity-power profile for each athlete.

\section{ACKNOWLEDGEMENTS}

This study has been partially supported by grants RTI2018-099723-B-100 of the Spanish Ministry of Economy and Competitiveness awarded to José Fernando Vera Vera and Luis Javier Chirosa Ríos.

All authors declare no potential conflict of interest related to this article

AUTHORS' CONTRIBUTIONS: Each author made significant individual contributions to this manuscript. AHO: preparation of the entire research project, substantial contribution to the design of the work, data analysis, writing, and intellectual content. DJM: preparation of the entire research project, critical review of the manuscript and its intellectual content. SGM: data analysis and intellectual concept. DMG: writing and data analysis. ARP: writing and data analysis. LAP: writing and data analysis. ICR: critical review of the manuscript and its intellectual content.

\section{REFERENCES}

1. Layer JS, Grenz C, Hinshaw TJ, Smith DT, Barrett SF, Dai B. Kinetic Analysis of Isometric Back Squats and Isometric Belt Squats. J strength Cond Res. 2018;32(12):3301-9.

2. Ojeda ÁH, Ríos LC, Barrilao RG, Serrano PC. Acute effect of a complex training protocol of back squats on 30-m sprint times of elite male military athletes. J Phys Ther Sci. 2016;28(3):752-6.

3. Tsoukos $A$, Bogdanis $G$, Terzis $G$, Veligekas $P$. Acute improvement of vertical jump performance after isometric squats depends on knee angle and vertical jumping ability. J Strength Cond Res. 2016;30(8):2250-7.

4. Winwood PW, Cronin JB, Brown SR, Keogh JWL. A Biomechanical Analysis of the Heavy Sprint-Style Sled Pull and Comparison with the Back Squat. Int J Sports Sci Coach. 2015;10(5):851-68.

5. Cross MR, Samozino P, Brown SR, Morin JB. A comparison between the force-velocity relationships of unloaded and sled-resisted sprinting: single vs. multiple trial methods. Eur J Appl Physiol. 2018;118(3):563-71.

6. Haun CT, Martin JS, Gleason BH, Kavanaugh AA, DeWeese BH, Stone MH, et al. Static jump test performance is related to back squat strength in athletes. Int J Sport Sci Coach. 2017;12(5):653-60.

7. Jiménez-Reyes P, Samozino P, García-Ramos A, Cuadrado-Peña V, Brughelli M, Morin J. Relationship between vertical and horizontal force-velocity-power pro fi les in various sports and levels of practice. PeerJ. 2018;6(e5937):1-18.

8. Rago V, Brito J, Figueiredo P, Carvalho T, Fernandes T, Fonseca P, et al. Countermovement Jump Analysis Using Different Portable Devices: Implications for Field Testing. Sports (Basel). 2018;6(91):1-15.

9. Healy R, Kenny IC, Harrison AJ. Assessing reactive strength measures in jumping and hopping using the optojumpTM system. J Hum Kinet. 2016;54(1):23-32.
10. Janowski M, Zieliński J, Włodarczyk M, Kusy K. Kinematic analysis of the block start and 20-metre acceleration phase in two highly-trained sprinters: A case report. Balt J Heal Phys Act. 2017;9(3):18-32

11. Rodriguez-Perea A, Jerez-Mayorga D, García-Ramos A, Martínez-García D, Chirosa L. Reliability and concurrent validity of a functional electromechanical dynamometer device for the assessment of movement velocity. Proceedings of the Institution of Mechanical Engineers, Part P: Journal of Sports Engineering and Technology. 2021, In Press.

12. Skurvydas A, Jurgelaitiene G, Kamandulis S, Mickeviciene D, Brazaitis M. What are the best isometric exercises of muscle potentiation ? Eur J Appl Physiol. 2019;119(4):1029-39.

13. Markovic G, Dizdar D, Jukic I, Cardinale M. Reliability and Factorial Validity of Squat and Countermovement Jump Tests. J Strenght Cond Res. 2004;18(3):551-5.

14. Andersen E, Lockie R, Dawes J. Relationship of Absolute and Relative Lower-Body Strength to Predictors of Athletic Performance in Collegiate Women Soccer Players. Sports (Basel). 2018;6(106):1-7.

15. Mcbride JM, Blow D, Kirby TJ, Haines TL, Dayne AM, Triplett NT. Relationship between maximal squat strength and five, ten, and forty yard sprint times. J Strength Cond Res. 2009;23(6):1633-6.

16. Jerez-Mayorga D, Chirosa L, Reyes A, Delgado-Floody P, Machado R, Guisado IM. Muscle quality index and isometric strength in older adults with hip osteoarthritis. PeerJ. 2019;7:e7471.

17. Carmona G, González-Haro C. Análisis de la capacidad de aceleración en mujeres atletas de modalidades de velocidad. Apunt Educ Física y Deport. 2012;107(1):69-77.

18. Cerda E, Jerez-Mayorga D, Machado R, Campos C, Guzman-Guzman I, Reyes A, et al. Validity and reliability of evaluating hip abductor strength using different normalization methods in a functional electromechanical device. PLoS One. 2018;13(8):e0202248. 